Articles

\title{
Trajectories to community engagement: Understanding older people's experiences of engagement with online and local communities
}

David Andrew Harley

Kate Howland

Eric Charles Harris
Senior Lecturer in Psychology, School of Applied Social Science, University of Brighton, United Kingdom

Corresponding Author.

d.a.harley@brighton.ac.uk

Informatics, Lecturer in Interaction Design, University of Sussex, United Kingdom

k.1.howland@sussex.ac.uk

Senior Researcher, Rica, United Kingdom

ericharris@rica.org.uk

The communal benefits of online communities and SNS are enjoyed by many Internet users but remain of limited appeal to many older people. In this study we consider how a small group of older people in the South of England engage with these technologies showing their motivations and the role of existing relationships in the local community with regards to this engagement. Four catalysts are identified which determine trajectories towards and away from online engagement and these are: family, roles, loss, and 'spaces and places'. The resulting trajectories are discussed along with their implications for policy making and technology design.

\section{Introduction}

\section{The experience of ageing in developed societies}

The experience of ageing is often accompanied by a shrinking social scene with retirement, the death of friends and family, and increasingly poor health and mobility (Bowling, 1994). Changes to family structures and the nature of local communities in industrialised societies

Harley, D.A., Howland, K., Harris, E.C. (2016). Trajectories to community engagement: Understanding older people's experiences of engagement with online and local communities. The Journal of Community Informatics, 12 (1), 104-127.

Date submitted: 2015-04-23. Date accepted: 2016-02-21. Copyright (C), 2016 (the authors as stated). Licensed under the Creative Commons AttributionNonCommercial-ShareAlike 2.5. Available at: www.ci-journal.net/index.php/ciej/article/view/1213 
often means that sources of companionship and social support do not emerge to compensate for increasing social isolation as expected in later life. The idea of 'family' as a stable source of support is no longer a given for those growing older in modern industrialised societies: families rarely remain in a particular locality from generation to generation and mass migration has become common for economic reasons. Generations tend not to live together or in the same neighbourhood (UN, 2007). Alongside these developments there is a shifting emphasis in developed societies towards individual choice rather than family responsibility and a growing ethos of 'independent living' amongst older people themselves (EC 2007). Here autonomy, self-reliance and self-determination are high on the agenda even into advanced age. Such changes have resulted in a trend towards solitary living amongst the older generation (UN, 2007) which further removes opportunities for social interaction, community participation and social support within older people's daily lives. Those living alone are more likely to report feeling lonely (Bowling, 2005) and this can increase susceptibility to depression (Choi and McDougall, 2009), alcoholism (Stanley et al, 2010) and dementia (Fratiglioni 2000).

\section{Older people's use of the Internet for social contact}

blah Older people commonly make use of communication technologies to maintain their social connections when long distances separate them. Historically this has been through 'old media' like the telephone, but computers and the Internet have opened up new avenues for social contact. Increasingly older people are turning to the Internet to maintain their social lives as they age, leading many governments to promote digital communication as a solution to the problems of social exclusion now being experienced by the elderly (e.g. Cabinet Office, 2014, EC, 2013). However the inevitability of such a shift is far from certain with the nuances of older people's Internet use and non-use still poorly understood.

When it comes to older people's social uses of the Internet, studies have so far shown how popular email is amongst this age group (Dickinson et al., 2005; Jones and Fox, 2009) particularly for keeping in contact with family and friends (Sayago and Blat, 2010). Whilst there has been some reluctance to adopt more recent online initiatives such as Social Networking Sites (SNS), studies do highlight similar family-oriented use on these sites (Karimi and Neustaedter, 2010; Gonzalez et al, 2012). It has been argued that older people's use of computer mediated communication (CMC) is primarily motivated by a need to ensure ongoing intimacy with existing friends and family (Lindley et al., 2008; Melenhorst, 2002) rather than as a source of new social contact. As such it is seen as being heavily influenced by socioemotional selectivity (Carstensen et al., 1999) which describes a tendency amongst older adults to gravitate towards pre-existing social contacts as a way of dealing with the ageing process. This tendency differs from the behaviour of younger Internet users who are more likely to prioritise opportunities for new social contact online (e.g. Brandtzæg and Heim, 2009; Lenhart and Madden, 2007). Socioemotional selectivity suggests that longstanding and emotionally intimate social ties become prioritised because older people perceive their time as limited in the face of approaching death. This present-oriented perspective prioritises social contacts that can maintain emotional stability around daily activities, a sense of purpose in life and the integrity of the self (Carstensen et al 1999). 


\section{Older people, online community and making new friends}

The Internet can be used as a source of broad social connection for older people beyond the bounds of familiarity, providing opportunities to start new friendships and engage with community online. Some older people use elder-specific online communities as a means of sharing interests, discussion and activities with their online peer group. A number of these communities have been studied to see just what it is that older users value on such sites (Wright, 2000; Burmeister, 2012; Xie, 2008). One of the earliest studies of SeniorNet (Wright, 2000a) suggested that companionship provided the most common background to new relationships emerging there. Wright (2000a) highlights the importance of companionship which is based on shared enjoyment and equality over social support relationships (i.e. those described by socio-emotional selectivity) which often carry obligation. Forms of social support were still evident within SeniorNet through the exchange of information (informational support) and to a much lesser degree - at $22 \%$ of those studied - through the sharing of problems and difficult emotions (emotional support). This latter group felt that their SeniorNet friends were like a 'surrogate family' (Wright, 2000b).

An ethnographic study conducted by Xie (2008) within the Chinese community OldKids also found companionship to be a major feature of relationships there and highlighted the importance of fun in enabling such relationships to flourish. Wright (2000b) also found fun ${ }^{1}$ and humour to be significant in this regard. Interestingly OldKids' use of different media channels supported development of relationships in nuanced ways: synchronous voice chat was most likely to be used for companionship, text-based forums were used for informational support and synchronous Instant Messaging was used for the most intimate forms of emotional support. There was also some evidence of instrumental support arising between users beyond the online context.

\section{Older people's engagement with 'open' social networking sites}

The development of Web 2.0 has expanded opportunities for social contact and online community by enabling users to interact and collaborate with one another as part of an ongoing social dialogue. It has also provided the means for users to create content as an implicit part of their web participation. Such developments could offer greater opportunities for older people to maintain their social connections and develop new ones but so far their enthusiasm for SNS has remained fairly limited. In the USA $27 \%$ of those over 65 have an SNS profile (Pew, 2014) whilst in the UK this figure is even lower at 9\% (Ofcom, 2013). The reasons for older people's limited engagement with SNS remain poorly understood. Studies so far have mostly examined older people's attitudes prior to adoption. Objections cited at this stage include a lack of knowledge and difficulty in using SNS functionality (Ryu et al, 2009) but also difficulty in seeing such computer activities as relevant or beneficial to older people, particularly in terms of enjoyment (Ryu et al., 2009), fun or communicative potential (Lehtinen et al., 2009). There is a clear dislike for the default 'open, sharing culture' implicit in such websites which places high expectations on personal disclosure and creates public

\footnotetext{
1 Nimrod's (2010) extensive content analysis of fourteen of the world's most popular elder-specific communities also identified "Fun online" as the most popular framing for older users" online interactions. In descending order of popularity the other topics were: "Retirement," "Family," "Health," "Work and Study," "Recreation," "Finance," "Religion and Spirituality,"

"Technology," "Aging," "Civic and Social," "Shopping," and "Travels".
} 
interactions which appear trivial or even dangerous to older users. Overall the lack of privacy and problems with social selectivity appear to be the greatest causes for concern (Lehtinen et al., 2009; Gibson et al, 2010; Righi et al 2012). Research engaging older users of SNS post adoption suggests that they appreciate SNS most when they use them to maintain connections with younger members of their family ${ }^{2}$ (Karimi and Neustaedter, 2011; Gonzalez et al, 2012; Nef et al, 2013). This suggests that they are similarly engaging in socioemotional selectivity (Carstensen et al., 1999) when weighing up the benefits of adopting such technologies. However it appears that SNS are not appreciated by the majority of older people and this is partly because they do not represent meaningful sources of social contact for them (Lehtinen, 2009).In this study we assess the significance of socioemotional selectivity in understanding older people's engagement with SNS and online communities by exploring the underlying motivations behind their engagement with these online resources.

In addition we consider the relationship between local and online community for older people. Research with younger users of Facebook has explored the relationship between use and social capital (Ellison et al, 2007), a measure of the cooperative potential available through Facebook as a social resource. This research has shown an emerging trend for university students to use this SNS as a way of reinforcing pre-existing emotional bonds (bonding social capital) as well as connect loosely with other new acquaintances (bridging social capital). Such uses may be particularly relevant to older users if they need to bolster local support because of declining mobility or reduced social opportunities. At present little is known about this offline to online dynamic for older users of SNS or online communities. Whilst similar effects have been shown for a broader Facebook demographic (Burke et al, 2010) such studies have not addressed older people specifically nor have they provided information about corresponding local (offline) contexts. In this study we consider how older users are involved in mapping their social relationships onto online communities and SNS from the baseline of local community involvement and show how these result in different trajectories towards and away from the online world.

\section{Aims and Objectives}

This qualitative study sought to capture the experiences, motivations and preferences of older people on the south coast of England. Research was conducted with older people of postretirement age with a view to understanding their experiences of local and online forms of community within the context of their everyday lives.

Our research questions were:

(1) What motivations exist at a local community level for older people to engage with SNS and other forms of online community?

(2) How does socioemotional selectivity play a part in participants' interest in online communities?

2 In this intergenerational context there is a concern that the transition to SNS may leave older people the wrong side of a new digital divide (Karahasanović et al, 2009); one where they are passive consumers of other (younger) people's contributions rather than being active contributors themselves. 
(3) How do older people's experiences and expectations of local community influence their attitude towards online communities?

(4) What are the different routes taken to engagement with local and online communities, and are there identifiable trajectories which are commonly taken?

\section{Methods}

A participatory approach was employed throughout, involving and consulting participants and community groups as part of the research process. Participants of retirement age were recruited through three different elder-specific community portals with a view to accessing participants with a diverse range of online and local community experiences. Additionally, a retired community leader took on an advisory role and attended project meetings to give feedback on methods and make recommendations on recruitment and sampling.

A deliberate attempt was made to recruit older participants with varying degrees of engagement with online community/SNS as well as those who had no online involvement at all. The community portals chosen included a local community organisation, a local computer club and an elder-specific online community based in the UK called DropBy (www.dropby.co.uk). An initial survey with 43 respondents was used to identify a suitably diverse sample which included an equal number of participants from the following: a) elderspecific online communities b) 'open' online communities through SNS, i.e. Facebook c) local computer club and d) those not online but connected to a local community organisation. This led on to fifteen individual interviews ${ }^{3}$ and a focus group ${ }^{4}$.

The final interviewees all lived independently in their own homes and were aged between 65 to 87 years with a mean age of 73.4 years. There were nine women and six men. The interviews were semi-structured and used an interview guide which explored five broad areas: 1) 'a walkthrough of yesterday' 2) different kinds of community 3) social relationships 4) technology and communication and 5) 'a walkthrough of yesterday online'. The interview was piloted with our community advisor to eliminate potentially confusing questions. Interviews took place in participants' homes and lasted approximately forty five minutes.

Analysis of the interviews was conducted using an inductive process of thematic analysis. The three authors each independently coded a sample of the transcribed interviews using NVivo software. Eleven codes were identified at this stage including: 1) family/friends; 2) trust; 3) risks/benefits; 4) barriers to engagement; 5) motivation; 6) shared values; 7) shared place/ space/history; 8) fun/work; 9) sense of belonging; 10) being alone: feelings of isolation/loneliness versus happy to be alone and 11) change. These codes were then compared across researchers and analysis was reframed around four recurrent themes or 'catalysts'. Researchers conducted a second coding of the interviews to explore these catalysts further. Finally individual trajectories were identified for each participant, taking into account their attitudes towards past, present and future use of community resources both online and locally. These individual trajectories were then grouped into five broad categories to show commons routes to engagement across the cohort.

3 One participant from the Facebook group later dropped out of the study.

4 Analysis of the focus group is not part of this paper. 


\section{Findings}

Our study was designed to investigate four key questions focusing on motivations for community involvement, the significance of socioemotional selectivity, experiences and expectations of community life and participants' differential routes to engagement with online and local forms of community. Here we address these questions directly using our four catalysts and five trajectories, to inform our responses and use direct quotes from our participants to illustrate particular points. In order to protect participant confidentiality no real names are used.

\section{What motivations exist at a local community level for older people to engage with SNS and other forms of online community?}

Our analysis identified four 'catalysts' which motivated initial moves to connect with community resources, establishing points of contact with the community at large, and dictating preferences for local versus online forms of engagement. These catalysts were family, roles, loss and 'spaces and places'. Here we outline the distinct features of these catalysts.

\section{Family}

Family provided an important conduit to the local community, giving a sense of purpose and aiding the process of making friends. Those who were particularly active in their local communities were often physically and emotionally close to their immediate family, seeing them regularly and being involved in their day to day lives. This on-going contact offered opportunities for informal meetings with other local people who were friends and acquaintances of younger family members. Establishing connections beyond the family was not always an easy task as Janet explains in relation to her relocation to Newhaven to help with her daughter's childcare,

"I didn't like Newhaven, I didn't feel I belonged to it at all, it was only the children, and as a result of that all my acquaintances, friends like those two there, are my daughter's friends, not mine” Janet

Regular contact with younger family also provided more formal opportunities for community involvement through school and sports club activities. In Janet's case this meant being asked to play the piano for all the children at her local school. Family relationships were also at the core of engagement with SNS, again supplying a sense of purpose in these online spaces. The preferences of family members with regards to particular communication technologies (e.g. mobile phones, texting, email, Skype, Facebook, etc.) were a strong motivating influence, determining the ongoing social practices of the family as a whole.

"I do email people. I thought, when I first got my laptop, this will be good to keep in touch with my family, but they don't really email. The younger ones do Facebook, even the older ones, one of my sons don't do Facebook, they don't do email, he doesn't phone either. I do think about Skype, maybe I could do that, but then again, if they're not doing it. If they're not going to be doing it, what's the point in me doing it? " Betty 
Those with a close emotional connection to their family (irrespective of physical distance) were likely to use family-preferred routes for maintaining such connections, often taking the lead from younger members of the family. To this end many of our interviewees (twelve out of the fifteen) had joined Facebook, primarily in order to keep abreast of events in the lives of their younger family. For some interviewees, using Facebook meant predominantly passively viewing posts of family members without comment, constituting a benevolent observation of their online lives as described by one interviewee,

"I've got a Facebook account but I only use it to go online and see what the rest of the family's doing" Carl

Engagement with Facebook was often accompanied by a sense of distaste at the triviality of exchanges, and an awkwardness at 'overhearing' their family's private conversations in this public arena. A number of interviewees described specific cases where they felt uncomfortable, which often highlighted differing intergenerational ideas about privacy and audience.

"I'm on the Facebook, but I mean, sometimes, I shudder when I see my grandsons talking to each other, and their language, and I think, oh, dear, but...Any rate, they probably forget that I can see it." Margaret

Viewing Facebook rarely translated into active engagement with family or others in this online space; family posts of significance were more likely to prompt direct personal contact with that family member through an alternative (more private) means, usually the telephone.

"I don't do a lot on Facebook, but I see something going on in my family that would probably make me think, oh, I'll phone them up and find out more about it. I just found out my sons just got an allotment. That was on Facebook!” Betty

Five of our participants had started to use Facebook in a more 'active' way, by posting their own content to the site. Three of these individuals had close relationships with family living nearby and used Facebook to augment their family and local community involvement. Facebook allowed them to maintain their family connections with a degree of independence, providing ways of expressing their family involvement without having to always be physically present. It also offered ways of extending their social network by getting to know the friends of their family before meeting them in person.

Roles

Social roles can be important in terms of maintaining an ongoing sense of identity and purpose for older people after retirement. By definition roles acquire their meaning in relation to particular communities or social groups. All of our participants had taken on roles within local community groups ${ }^{5}$ like residents' associations, community centres, churches and faith

5 This may also represent a bias in our sample which was accessed via various community group memberships. 
groups, children's after school clubs, local charities, exercise classes, bowling clubs, art, knitting, tailoring, computing, lunch and travel groups. Many had assumed quite active roles in these groups such as trustee, treasurer, organiser, administrator, teacher or general helper, as well as engaging as users or beneficiaries of other groups. Some of these roles also informed and motivated engagement with online communities.

Many of our participants assumed roles that made use of skills they had gained during their working lives, such as Peggy's accounting skills for her role as treasurer or Ben's skills in computing and teaching for running the computer club. In other cases the volunteering roles made use of more general skills such as Peggy's driving for 'meals on wheels' or Marie's selling refreshments and making tea at her grandchildren's football club. What can be seen as common to all these roles, and the way our participants talked about them, is the importance of being able to make a useful contribution and to 'give something back' to their local communities, whilst also recognising the benefit to themselves.

"I can get something back from doing something for somebody else. Do you know what I mean? ’Margaret

Whilst our participants might assume responsible roles in relation to certain community groups, they were also quite happy to be users of other clubs, services or community centres. This ability to move in and out of responsible roles appeared to be another feature of these older people's voluntary engagement where the ability to maintain such roles might change over the years, from a more active role at the beginning through to later on being a passive user.

In comparison to the multitude of explicit local community roles, online communities and SNS did not offer our interviewees such well-defined roles. The only 'official' roles assumed online were those which extended local community responsibilities through the creation and administration of online groups through email lists, Facebook and DropBy groups. Ben for instance was the administrator of an online group in DropBy for members of the computer club, and one on Facebook for a Film Society which he ran at the local community centre. Administration of such groups was approached in such a way as to ensure privacy and safety for group members. On DropBy, new members were actively engaged in conversation from the beginning in order to assess their authenticity as prospective members and to make them feel welcome. Unfortunately this kind of hierarchical surveillance or gatekeeping was not perceived by all the members as necessary or helpful for group dynamics.

Generally speaking, online roles were more implicit than this, emerging as a result of stances taken during online interactions rather than explicit role choices. The predominant family context within Facebook meant that the most common social role for our participants was that of the passive observer as described here,

"Three of the grandchildren are on Facebook but we very rarely exchange messages. Simply because I don't want to embarrass them because I'm out of their generation and I don't want to spy on them." Iris

Beyond this passive online stance six of our interviewees had established Internet roles based on fun and light-hearted engagement, posting jokes and humorous videos to online communities and playing word games with friends through Facebook. 
"I post stuff that I like you know...my basic aim in going online is, going anywhere, is to either be amused or to learn something so the other website that I probably spend more time on than DropBy is Reddit " Carl

The online roles of sharer, humorist and game player were emergent and implicit, arising as a personal interpretation of online communities and SNS.

\section{Loss}

Loss is an inherent aspect of the ageing experience, present in the lives of all of our participants. It was perhaps most poignantly experienced through bereavement with the death of a spouse or close friend but other forms of loss were also apparent. The loss of significant roles in life and failing health and mobility were also common experiences in retirement, which challenged individual autonomy and forced a reassessment of social relationships. The challenge of loss was often countered by greater involvement with community groups and activities particular those involving one's peers.

This affected the women in our study more than the men, with five of our nine female participants having lost their husbands and none of the men having suffered similar bereavements. This caused these women to reflect upon having previously adopted a somewhat insular life with their spouse, and a sense of not needing anyone else while they had each other. This had led to feelings of isolation after the loss of their spouse, and an eventual need to reach out and build new relationships with peers.

Loss was often accompanied by a heightened sense of loneliness and a feeling that the home was no longer a place of comfort in the same way it had been before. Some of those interviewed said that there was a point when they found being at home alone unbearable and had to get out and find somewhere else to be as Joanne explains,

"My husband died three years ago and I'd looked after him for a couple of years so I was more or less isolated at that time and I realised that I didn't want to stay at home and there are quite a number of ladies who have that; they don't like staying at home alone" Joanne

Involvement with community groups and activities helped assuage these feelings of loneliness and provided a new sense of purpose in life. Communal groups and activities, particularly those involving peers, provided a degree of companionship and understanding which was not always possible elsewhere (even from family members). It was felt that sharing the experience of loss was sometimes easier with another older person who was more likely to have experienced similar losses as Larry explains,

"it is such a benefit, when your partner dies, and you can, if you want to, you can go down the bowls club, and see your friends, and they'll all help you over this, because most of them have been through it" Larry

Online community had a role to play here in connecting those with similar experiences of loss and allowing them to share the difficult emotions involved. This need for companionship and mutual understanding was met through engagement with elder-specific online communities as well as those designed specifically for the bereaved. Two of our interviewees 
made connections in this way. Here Daphne explains how she made a new friend through this kind of an online connection,

'I met her about four years ago on a widows' forum. We both recently lost our husband and we just seemed to click somehow and we speak practically every day which is nice. It's just a shame that she's so far away" Daphne

Daphne had never met this friend in person, but did express a wish to do so one day. For others experiencing bereavement, the physical presence of local community was more important in terms of providing opportunities for shared meaningful activity outside the home. Facebook, online communities and the Internet more broadly were used in times of grief as sources of local contact with opportunities to meet people face to face.

\section{Spaces and Places}

The characteristics of both the available physical places and virtual spaces have a clear role to play in encouraging or discouraging community engagement. Sharing a geographical location and physical space were often precursors to community involvement for this group of older people. Our interviewees discussed many local places that acted as meeting points and catalysts for community engagement on an informal level. Almost all interviewees spoke about the importance of places such as pavements outside homes, parks, bus stops, local shops and doctors' surgeries in making connections with local people. In these places there was no guarantee of shared interests, but a likelihood of a shared experience of the physical neighbourhood and the routines associated with daily living in a certain place. As Iris explained in relation to her shopping excursions to the local shops,

\section{"I may bump into one or two people I know. Sometimes I go in the morning and sometimes I go in the afternoon but I do bump into some of the people I know and we stop and have a chat" Iris}

These everyday places allowed people to come together for the implicit sharing of life experience without an expectation of an enduring emotional connection and often formed the basis of 'being known' in a modern local community, developing over time. In some cases these local spaces were the source of lasting reciprocal friendships as Bryan described in relation to his neighbours,
"a lady and her husband opposite who I pick blackberries for and go and visit. I don't do just that for them. They do things for me and I do things for them, it's a reciprocal thing "Bryan

Local community centres were seen by many of our participants as the natural place to go if they wanted to make an explicit effort to meet people and get involved with 'community'. In this context participation focused on formal activities such as art classes or computer clubs with informal conversations taking place over coffee or lunch. Both forms of interaction were seen as important for communal feelings to take root. Many of our interviewees highlighted the importance of shared interests and activities for establishing friendships and community ties. Specific locations and contexts were seen as indicators of the likelihood of finding people who shared these things. Again the shared activity (such as classes) legitimised their 
copresence and acted as a safe way of allowing friendships to develop without there being pressure if this did not happen.

Some participants had also experienced community engagement through virtual spaces, including online forums and SNS. Here the nature of shared space was defined differently, in terms of ideas and computer-mediated activities rather than the physicality of a setting and accompanying activities. For some a shared focus of discussion was a sufficient motivation for engaging with an online community. Three of the men in our study engaged with Twitter for news, politics and current affairs. One of these men Carl was also a regular contributor and reader of the social news site Reddit, which he visited every day with the view that,

"there's a lot more like minded people online, especially on Reddit" Colin

For other interviewees, playful spaces created for game play sparked an engagement with online community. Three of our female interviewees played social games through Facebook including online versions of Bingo and Scrabble. These games encourage social interaction alongside gameplay using a separate text-based chat window. This allowed informal connections to develop alongside the game. Usually these games were played with people they already knew locally but not always. Marie played Bingo in a 'public room' and had developed a lasting friendship with someone that she had met whilst playing there. This developed into regular conversations via email with them meeting in person some months later.

In other cases gregariousness and enjoyable social interaction were all that was needed to frame the online space. This was particularly true of those involved with elder-specific online communities (including DropBy). Daphne had developed a strong sense of belonging to a particular group of users that she had met whilst using the forums within such an online community. This group was made up of around 16 people and had persisted as a group despite having to migrate to different sites a number of times. Interestingly Daphne described them as her 'local' forum even though its members were from all over the UK and abroad. When asked about her use of this term, she explained,

"Yeah, local online. Yeah, I shouldn't really use the word local should I really...they're scattered all over the country, because one of them's in Spain, he lives in Spain, but I don't, when I'm talking to it, I don't look at it that they're all over the country, we're just, sort of in a room together if you like... I think that I can honestly say that I'm closer to them than what I am my family" Daphne

What was interesting here was the way that the emotional closeness of the group members had been translated by Daphne into a physical closeness to justify the feelings of closeness that she had to the group. This was unusual amongst our participants who were usually keen to transcend the online to local divide and meet people in person as much as possible, as a way of transforming these online connections into 'real' ones. Daphne was also keen to meet these people in person but a chronic illness made travelling very difficult.

All of our interviewees who had joined DropBy did so in the hope of making or sustaining local connections. They expressed disappointment that other members of the online community were so far away and indicated that they had hoped to make contact with more 
local people. Similarly much of our participants' activity through Facebook extended local connections by engaging in interactions relating to real world spaces and places. Sometimes this was also set up as an online bridge to connect with local people online such as the Facebook group set up by Ben for the film club that he ran at the local community centre.

\section{How does socioemotional selectivity play a part in participants' interest in online communities?}

As the catalysts show the presence of family online was a significant motivation for our participants to go online themselves and get involved with certain forms of online community. Strong family ties and a prevailing use of Facebook amongst family members were likely to steer them towards Facebook as well. Socioemotional selectivity (Carstensen, 1999) suggests that older people are likely to gravitate towards people that they already know and have some emotional connection with (i.e. close family and friends) as they get older. Our participants' use of Facebook was largely family-centric or concerned with maintaining existing friendships .

"[A]ll my friends on Facebook are people who have been friends, physical friends. College friends, they may be people that... I suppose the good thing is that you can have a online friendship, but you may not see them for ten years." Ben

This suggests that socioemotional selectivity may be at play with regards to Facebook use in particular. However this was not the whole story. Family ties were not always central to these older people's daily lives. Some of our interviewees had quite weak connections to their family and did not rely on them for a sense of ongoing involvement in life whether locally or online. Even those with strong family ties still maintained activities and friendships beyond the purview of family. Communal activities and group membership with peers were important for all of our participants as they provided independence away from family: opportunities for meaningful activity, a source of companionship and opportunities to make new friends.

Those of our participants who were online also joined communities there. Often their involvement with these communities was an incidental part of their Internet use, occurring through interactions in anonymous online spaces; places like Twitter, Reddit and eBay where common interests were shared with other Internet users but with no expectation of any enduring relationship. These same participants had also joined online communities with the explicit intention of meeting and interacting with new people. Four of our participants had developed significant new relationships with the people they had met online, through quite diverse routes including dating sites, bereavement forums, elder-specific online communities and through Facebook games,

"[Y]ou can make friends on Facebook and in fact..I made a friend, well various friends... and you chat to them and play a game or invite them to play a game with you, and that sort of thing... but one particular friend that I seem to get on with quite well... I think we were playing some game or other on Facebook and she put a comment to me and we started chatting." Marie 
These emerging online relationships show our participants seeking contact with previously unknown others not on the basis of emotional safety as socioemotional selectivity might suggest but out of gregariousness and a sense of fun.

In addition, the online presence of family members did not always steer an older relative towards greater use of the Internet, with some family members being particularly unhelpful or obstructive. The willingness of younger family members to help older family with such technologies was variable. Janet for instance who did not use the Internet at all decided that genealogy websites might be interesting to her.

"All I wanted to do really was to do my ancestry". But I haven't done that yet. I'd quite like to do that but they are always so busy when I see them, my daughters, trying to cook meals and get children off to bed and so forth. My son-in-law says he'll do it but I don't know when" Janet

Bakardjieva (2005) highlights the importance of 'warm experts' when teaching older people to use the Internet, i.e. people who the older novice knows that have superior knowledge of computers and the Internet but also have a personal connection with and degree of trust that allows them to support their learning in their own home. In this study there were a number of examples of what might be called 'lukewarm experts' within our interviewee's families, i.e. younger family members who acknowledged the significance of the online world to their older relatives but were unable or unwilling to spend time with them in order to teach them how to use it.

\section{How do older people's experiences and expectations of local community influence their attitude towards online communities?}

For most of those interviewed, the blueprint for community had its roots in the family, with a suggestion that 'real' community could only occur through extended family connections in a particular geographical location. This understanding was mostly historical and came through in childhood memories like Joanne's,

"being brought up in a small village, the sense of community there is tremendous actually and it can't be compared, I haven't been able to compare that with anything else, not really. Living there I had a huge family, I had cousins, six, seven cousins, you know, that sort of thing. But beside that one knew - and I was only a child and I felt I belonged there and I still feel that is where I really belong" Joanne

A significant part of this community feeling had been the experience of 'being known'. In childhood this had meant whole families knowing one another in a particular street or village. Now this was less common with family members often living some distance from one another in different areas of the country or abroad. Nonetheless, the possibility of 'being known' remained an important aspect of community feeling in the present. Two particular ingredients were seen as key to this: the opportunity to physically meet up with other people and there being a suitable number of people present. Physically meeting up and talking to

6 a reference to using the genealogy site Ancestry.com 
people face to face was seen as an intrinsic part of generating a community feeling as Daphne explained in simple terms,

"community is where people meet up and socialise" Daphne

Despite the geographical dispersion of families all our participants were keen to emphasise the importance of this for maintaining family bonds. The same was true for involvement with local community groups. Community feeling was also seen as dependent upon a critical number of people being present in a particular place, as Carl explained,

"to me community it's gotta be small, it's containable" Carl

The specific number was difficult to pin down but it was felt that having too many people could easily destroy feelings of belonging to a group. Overall our participants believed that their experience of community had changed irrevocably during their lifetimes (particularly with regards to family relocations), and would never return to the way it had been in the past. Perhaps understandably their views on community generally left them unconvinced about the possibilities for online community. The reasons given for this were that the Internet was too impersonal a medium for social contact to be emotionally satisfying. Given their emphasis on face to face meeting this was unsurprising. Some went as far as to say that online-only relationships were slightly unreal.

"They are nearer to being characters in a book... in the way that you relate to characters in a book, you relate to characters you know only via the Internet" Iris

\section{What are the different routes taken to engagement with local and online communities, and are there identifiable trajectories which are commonly taken?}

The four catalysts were influential in defining our participants' individual trajectories encouraging them towards, away and between local and online forms of community in various ways depending on their individual circumstances. Whilst these trajectories were idiosyncratic, commonalities did emerge in relation to the catalysts previously defined, showing five distinct trajectories. Here we outline these different trajectories:

\section{Trajectories moving towards greater online community engagement}

Here we consider those participants who were keen to become more involved in online forms of social contact.

\section{Trajectory 1: Family-focussed Internet User}

Five of our participants had trajectories which were largely based on family contact. They were all spurred on to greater engagement with the Internet through a desire to develop better connections with family at a distance. Sometimes this distance was not great, with family living in the same town but all at distances sufficient enough to interrupt ongoing family life. Online spaces that were used to connect with family included email, Facebook and Skype. These were initially seen as spaces for engaging with family and existing friends (near and far) but online relationships had later emerged either through friends of family online or 
independently via other online spaces. This group had all started to use computers and the Internet for the first time during retirement. They had made use of local spaces and places to learn the literacies associated with online communication, and had enlisted the help of family and community groups (principally the computer club) to acquire the necessary skills. Their online activities did not detract from local involvement with them all being engaged in local community organisations although they tended to assume member roles with positions of limited responsibility. Loss was a factor for some on this trajectory, with two participants having lost their husbands. In both cases this had encouraged greater involvement with family, local community and online community. Participants on this trajectory covered the whole spectrum of ages from their mid-sixties to mid-eighties.

\section{Trajectory 2: 'Internet as Local Community Tool'User}

These four participants also had close relationships with their family, but had acquired a proficiency with computers and the Internet before retirement. This meant that they were adept advocates of the technology and had a broad focus for their computer-mediated activities which stretched beyond family. People on this trajectory had retired in the last 5-10 years and had taken on roles of responsibility within local community groups post-retirement, including treasurer, trainer and chair. These roles often drew on skills developed through past professions which included digital skills. They were just as likely to use computers and the Internet to coordinate local community activities as they were to make contact with family and friends. They were all heavily involved in their local community and used online spaces including email groups, DropBy and Facebook groups to support this offline local community involvement rather than it representing a purely virtual activity. Whilst these participants had strong digital skills, they still expressed a preference for face-to-face interaction with individuals in real world places. Some had made new contacts and potential friends online, but felt that an in-person meeting was necessary to cement the relationship. All the people on this trajectory were married and lived with their partners. Loss was not a major factor in their lives: participants were in their mid to late-sixties, and none had lost their partner.

\section{Trajectory 3: Independent Online Friend Seeker}

The two participants within this group were at risk of becoming socially isolated, having experienced difficulties with family relationships and connections in their local communities. They had become more reliant on virtual relationships as a source of ongoing social connection. These participants were at the younger end of the spectrum from mid-sixties to early-seventies and had well-honed Internet skills developed through past job roles, or through early adopting family members. Both had suffered from loss in their lives, one through bereavement and the other through divorce. These events had resulted in an emotional distancing with certain relatives that had disrupted family life. Both lived alone and had some members of their family living local. However they did not have particularly close relationships with family and did not have regular contact. In addition their links to local community were poor, one due to mobility issues and the other due to relocation after his divorce. They had struggled to find real-world places where they could engage with a community, but had been very active in seeking community in online spaces such as forums and social networking sites. Neither had active roles in their local communities but both had taken on informal but distinctive roles online. These roles were self-selected and included 
humourist and active content poster as well as contributor to a bereavement forum, providing support for others.

\section{Trajectories moving towards lesser online community engagement}

Here we consider those participants who were making a deliberate choice to avoid online forms of social contact.

\section{Trajectory 4: Isolated Internet Rejecter}

Only one of our participants fitted this trajectory ${ }^{7}$, which is characterised by social isolation and frailty, compounded by not having any digital skills to rely on. A lack of motivation to learn about or use the social aspects of the Internet also follows from this, and a dismissive take on such usage when encountered through younger family and the media. This was one of our older participants, in her mid-eighties, having experienced loss in the form of bereavement when her husband had died some years earlier. She now lived alone and had become increasingly isolated. She did not have children and had no close family living nearby, but had some family living at a distance who she spoke to on the phone regularly but saw rarely. She had a few friends in the local area but did not see them regularly because her mobility was limited. She did not talk about work in her past, and her main role had been as a housewife. She had no previous experience of online activity or digital skills and was not interested in developing these. What she had heard about Facebook from younger family she found quite distasteful. She thought that there was no substitute for face to face communication. Her access to local community spaces was limited given her mobility but she was a member of a local community transport scheme. She did not have active roles within community groups. Her immediate local neighbourhood provided a space where she was known to a degree but no regular interactions took place there. She occasionally had interactions with neighbours when there was a crisis.

\section{Trajectory 5: Post-retirement Internet Rejecter}

The three participants in this trajectory were in their seventies, lived alone and relied on local relationships to sustain them socially. Only one participant in this trajectory had close family nearby. Whilst this group were familiar with computers and the Internet, having used them as part of their prior working roles, they were not keen to make use of them as routes to social contact. They did have some skill in computing, but typically saw computers as being work machines and not tools for communication or entertainment. There was little interest in online virtual spaces such as social networking sites, which were seen as slightly trivial and not relevant to their lives. Participants on this trajectory had experienced loss of some sort. Two were divorced and all were experiencing some degree of loss with regards to physical or cognitive faculties. All had access to local community spaces where they had taken on active volunteering roles, but were now finding that they had to give up some of their responsibilities and take on less active roles because of increasing frailty.

7 Undoubtedly there are other people who would fit with this trajectory but they were perhaps unlikely to volunteer for this kind of a study in the first place. 


\section{Discussion}

Social isolation is a central issue being addressed by this study, with our interviews highlighting the ways that the social resources of local and online communities were enlisted differently by our participants to maintain social cohesion in their everyday lives. Older people in developed societies are now more likely to live their later years physically separated from family and friends and are at risk of being more socially isolated than ever before in their local communities (McCarthy and Thomas, 2004; Lee, 2006). When social isolation is experienced as loneliness it is often detrimental to the wellbeing of older people (Tomaka et al, 2006) and encouraging greater community engagement is one way of addressing this.

Our research suggests that a better understanding of the four catalysts identified (family, roles, loss, spaces and places) and older people's digital trajectories will be important if we are to provide greater opportunities for community engagement by older people through online communities and SNS. Our trajectory analysis indicated that those who are most socially isolated in their local communities are less likely to engage with online community, except where they have existing technical skills. Given the lack of 'warm experts', even for many of those with family member living nearby, there is a need for additional support and interventions if online communities are to be of any benefit to the socially isolated.

Here we reflect upon how the potential of these catalysts and trajectories might best be tapped by future interventions considering both social and design aspects

\section{Social Interventions}

\section{Shifting the emphasis beyond the family context}

Family was significant in determining a general awareness of the Internet and engagement with SNS through Facebook despite misgivings about the trivial and public nature of interactions there. This was in line with socio-emotional selectivity (Carstensen et al, 1999). However alternative social motives were apparent in relation to other forms of online community. There was a general willingness amongst our participants who had some digital skills to engage with strangers, make new friends and take social 'risks' online through fun and light-hearted interactions. This challenges the use of socioemotional selectivity as a singular model for understanding older people's use of online social resources. Research into identity in later life suggests that a number of different identities are important for maintaining wellbeing (Moen et al, 2000). Whilst one's family identity is often the most significant one (e.g. as a spouse, parent or grandparent) there are other relationships and identities that are equally important. It seems that socioemotional selectivity may be an aspect of family identity but that is not the whole story. There is more to an older person than that which their family sees.

In addressing older people's social isolation and loneliness it seems pertinent to provide opportunities for developing new identities online as sources of self expression and relatedness. Employing socio-emotional selectivity (Carstensen et al, 1999) as a guiding principle is likely to limit such social opportunities. Some elder-specific online communities like DropBy and the now defunct SagaZone (www.sagazone.co.uk) have taken a similar risk- 
averse approach to online community, striving to create safe environments for potentially vulnerable older users. They have done this by encouraging transparent self-disclosure and top-down moderation of interactions in order to reduce online abuse and deception. Whilst this may be appropriate for some older users, many of our participants were interested in a more 'open' approach to online interactions where the benefits of anonymity were acknowledged for sharing difficult emotions and making new friends. Clearly there is a balance to be struck between safety and openness in online communities that are still establishing themselves.

\section{Increasing opportunities for peer learning}

Family support was significant in promoting the idea of Facebook use amongst our participants, with younger family often being instrumental in creating an initial profile on the site. However family support for learning how to use this SNS was variable. Bakardjieva (2005) discusses the need for 'warm experts' with appropriate knowledge and patience when teaching older people to use the Internet. In this study we uncovered a number of examples of 'lukewarm experts' within our interviewee's families. These were typically younger family members who recognised the potential benefits of the online world for their older relatives, but were unable or unwilling to spend much time teaching them how to use the Internet. For a number of our interviewees, a peer-led computer club afforded the best opportunities for developing their online skills, and receiving guidance from 'warm experts'. We would suggest that providing opportunities for greater peer learning would allow older people to learn about SNS and online community in a way that is more aligned with their particular learning difficulties and age-appropriate motivations.

\section{Design Initiatives}

\section{SNS within and beyond the family}

Family connections were often the starting point for broader community participation both in the past and present. However there are aspects of the design, administration and culture of SNS that do not encourage older people to actively engage with them and exclude them from family interactions that take place there. In particular the general lack of privacy and the triviality of public exchanges within Facebook were problematic for most of our participants. The general blurring of public/private boundaries and the expectations of personal disclosure within Facebook (and SNS) culture acted to negate family exchanges for many of our participants. Online spaces which supported a clear transition from public to private interactions were more conducive to growing intimacy (e.g. chat windows in Facebook games) and should be provided and made more accessible in SNS. The addition of 'family rooms' to Facebook functionality would be of great benefit to older users who are primarily motivated by family contact. In this way privacy could be ensured amongst family member along with more intimate exchanges.

Conversely public anonymity was seen as a beneficial aspect of the Internet that was missing from more closed environments like DropBy. The disinhibition associated with anonymous online interaction (Burke et al, 2010; Suler, 2004) can allow emotions to be expressed in ways that may not happen with existing family and friends. The establishment of an 
anonymous 'sharing space' would be particularly important for those wishing to share the difficult emotions of loss that accompany ageing particularly bereavement.

These relationships enabled a degree of independence from family allowing them to maintain their own sense of identity in the face of life changes. All of our interviewees were involved in group activities with their peers in one way or another and the nature of these groups was diverse. Overall there was an emphasis on shared endeavour but also fun and light-hearted companionship. There was an openness to meeting new people and starting new friendships.

\section{Online roles}

The importance of social roles in retirement has long been acknowledged as a significant part of healthy ageing (Havighurst and Albrecht, 1953) and community cohesion, with it underpinning a great deal of government policy aimed at older people's wellbeing (WHO, 2002). In this study social roles were shown to motivate local community involvement, providing structured activity and a renewed sense of identity and purpose post retirement. Unfortunately most SNS and online communities do not encourage people to identify themselves through specific roles and this is likely to discourage older people's prolonged engagement with them. In this study the lack of meaningful involvement was evident in our participants' perceptions of Facebook interactions as trivial. Establishing online roles may be an important way of easing older people's integration into SNS and other forms of online community. Such roles would have to support their active contribution to the community and make use of existing skills and experience.

Roles tend to emerge more implicitly online like the 'answer person' in a discussion forum (Gleave et al, 2009). In this study implicit roles emerged in the form of family observer as well as sharer, humourist and game player to the broader Internet audience. Some of these could form the basis of more formal roles within SNS and online communities as curators of family memories/genealogists, moderators of online discussions or online tournament organisers. The more explicit development of such roles could lead to greater engagement by some older users.

\section{'Being known'online}

It was clear from our participants' accounts that group size was very important with regards to establishing a feeling of community. A number of our participants noted that when a community group got over a certain size something fundamentally changed for the worse. This emphasises the importance of 'being known' within a community where everybody is aware of everybody else's presence and knows their own particular qualities and skills. There are clearly limits to how many people can be known in this way and the feeling of 'togetherness' is therefore limited by the number of community members. This same principle seemed to reassert itself online with Daphne maintaining her 'local' online group feeling with sixteen others whilst many others expressed a lack of community feeling in relation to large communities like Reddit or Facebook. SNS by definition encourages a porous notion of community where the boundaries of friendship and family are blurred. Friends of friends and tangential group affiliations are all incorporated into representations of the group consciousness (e.g. Facebook timelines and Twitter feeds). This makes it impossible to have a feeling of knowing and 'being known' by all present. If SNS and online communities are to encourage older users' engagement they must first provide ways of 
restricting group membership appropriately and offer transparency with regards to who is privy to their online interactions.

\section{Hyperlocal: the Internet as local resource}

Access to local, face to face social interaction was still the litmus test for online community for our group of older people, mostly reinforcing local bonds and resulting in actual meetings. We found our participants using Facebook and DropBy as tools for maintaining and exploring local connections, with disappointment being expressed by some interviewees that DropBy did not have as many local members as they had expected. We would suggest that this emphasis on 'hyperlocal' ( $\mathrm{Hu}$ et al, 2013) uses of social media is something that could be explored further with the older generation through the design of community initiatives which make use of the Internet to support local community interactions. Indeed DropBy itself is an online community that has started to pursue this approach by organising local lunch events for community members who live in a particular geographical location. Such local/online initiatives should be explored in further research.

\section{Recognising Older People's Different Trajectories to Community Engagement}

There is a growing 'digital imperative' in developed nations which suggests that increasing digital literacy is an obvious and desirable aim for older people if they want to feel included and empowered in modern societies (e.g. Cabinet Office, 2014; European Commission, 2013).The different trajectories identified in this study show that there is nothing inevitable about a shift towards the online world for older people. Multiple trajectories were identified which moved away from online contact as much as towards it.

Those with family online were the most likely to move towards greater online involvement. A lack of this family-based social motivation was significant in determining our participants' avoidance of the Internet altogether even when they had some of the necessary digital skills (our post-retirement Internet rejecters). Social exclusion was ameliorated to some extent by digital skills but also by an awareness of the Internet as a social medium which requires a certain online gregariousness - a willingness to engage with strangers online if one is to make new friends.

Despite these different attitudes towards the Internet, all of our participants expressed a clear preference for face to face meetings as a basis for community. There was clear resistance towards the online-only or "digital by default" trends that exist in public discourse and emerging social norms.

\section{Conclusions}

SNS and other forms of online community have potential for ameliorating social isolation and loneliness amongst older people. In this study they were shown to provide many of our older users with opportunities for maintaining their connections with family and friends. In addition they offered new ways of interacting with strangers and developing new friendships. The four catalysts identified (family, roles, loss and 'spaces and places') highlight some of the dynamics that need to be addressed in order to create online communities that are more appropriate and interesting to older users. They invite a revised approach to online 
community which accommodates older people as a heterogeneous user group with diverse motivations. We argue for an approach that acknowledges their 'whole selves' rather than solely defining them by family-centric or risk-averse models of vulnerability. The trajectories identified show the significance of family in addressing digital and social inclusion as well as an 'online gregariousness' in relation to making new friends. They also show the continuing significance of face to face interactions as a basis for community. In this paper we have proposed a number of social and design interventions based upon our four catalysts and five trajectories which are intended to promote greater engagement within online community by older users. The generalisability of this study's findings are limited however due to the small sample size and an implicit bias towards community-oriented individuals within that sample. Engaging older people who are more socially isolated will be an important challenge for future research in this area.

\section{References}

Bakardjieva M. (2005). Internet Society: The Internet in Everyday Life. London, Thousand Oaks, New Delhi: Sage.

Barak, A., Boniel-Nissim, M., \& Suler, J., (2008). Fostering empowerment in online support groups. Computers in Human Behavior, 24(5), 1867-1883.

Bowling A. (1994). Social networks and social support among older people and implications for emotional wellbeing and psychiatric morbidity. Int Rev Psychiatry 1994 (6), 4158.

Bowling A. (2005). Ageing Well. Quality of Life in Old Age. Maidenhead: Open University Press.

Brandtzæg, P. B., \& Heim, J. (2009). Why people use social networking sites. Online communities and social computing, 143-152. Springer Berlin Heidelberg.

Burke, M., Marlow, C., \& Lento, T. (2010). Social network activity and social well-being. Proceedings of CHI 2010, ACM, 2010, 1902-1912.

Burmeister, O. K. (2012). What seniors value about online community. Journal of Community Informatics, 8,1 .

Cabinet Office (2014). Government Digital Inclusion Strategy. https://www.gov.uk/ government/publications/government-digital-inclusion-strategy/government-digitalinclusion-strategy\#1

Carstensen, L. L., Isaacowitz, D. M., and Charles, S. T. (1999). Taking time seriously: A theory of socioemotional selectivity. American Psychologist, 54, 165-181.

Choi, N. G., \& McDougall, G. (2009). Unmet needs and depressive symptoms among lowincome older adults. Journal of Gerontological Social Work, 52(6), 567-583.

Dickinson, A., Newell, A. F., Smith, M., and Hill, R. L. (2005). Introducing the Internet to the over-60s: Developing an email system for older novice computer users. Interact. Comput. 17 (6), 1-22.

Ellison, N. B., Steinfeld, C., \& Lampe, C. (2007). The benefits of Facebook "Friends:" Social capital and college students' use of online social network sites. Journal of Computer-Mediated Communication, 12(4), article 1. 
European Commission (2007). European i2010 initiative "Independent Living for the Ageing Society” http://ec.europa.eu/information_society/activities/policy_link/brochures/ documents/independent_living.pdf

European Commission (2013). Digital agenda for Europe: A Europe 2020 initiative. http:// ec.europa.eu/digital-agenda/digital-agenda-europe

Fratiglioni, L. (2000). Influence of social network on occurrence of dementia: a community based longitudinal study. The Lancet, 355, 9212, 1315-20.

Gibson, L., Moncur, W., Forbes, P., Arnott, J., Martin, C., \& Bhachu, A. S. (2010). Designing social networking sites for older adults. Proceedings of the 24th BCS Interaction Specialist Group Conference (186-194). British Computer Society.

Gonzalez, V. M., Jomhari, N., \& Kurniawan, S. H. (2012). Photo-based narratives as communication mediators between grandparents and their children and grandchildren living abroad. Universal Access in the Information Society, 11, 67-84.

Gleave, E., Welser, H. T., Lento, T. M., \& Smith, M. A. (2009). A conceptual and operational definition of'social role'in online community. System Sciences, 2009. HICSS'09. 42nd Hawaii International Conference on (1-11). IEEE.

Havighurst, R., J. and Albrecht, R. (1953). Older People. London: Longman.

Hu, Y., Farnham, S. D., \& Monroy-Hernández, A. (2013). Whoo. ly: Facilitating information seeking for hyperlocal communities using social media. Proceedings of the 2013 ACM annual conference on Human factors in computing systems (3481-3490). ACM.

Jones, S., \& Fox, S. (2009). Generations online in 2009. Washington, DC: Pew Internet \& American Life Project.

Karahasanović, A., Brandtzæg, P. B., Heim, J., Lüders, M., Vermeir, L., Pierson, J., Lievens, B., Vanattenhoven, J., and Jans, G. (2009). Co-creation and user-generated contentelderly people's user requirements. Computers in Human Behavior, 25 (3), 655-678.

Karimi, A. and Neustaedter, C. (2011). My grandma uses facebook: Communication practices of older adults in an age of social media. Technical report, Simon Fraser University.

Lee, M. (2006) Promoting mental health and well being in later life: A first report from the UK Inquiry into Mental Health and Well-Being in Later Life. London: Mental Health Foundation and Age Concern.

Lehtinen, V., Näsänen, J., \& Sarvas, R. (2009). A little silly and empty-headed: older adults' understandings of social networking sites. Proceedings of the 23rd British HCI Group Annual Conference on People and Computers: Celebrating People and Technology (45-54). British Computer Society.

Lenhart, A., \& Madden, M. (2007). Social networking websites and teens: An overview. Washington, DC: Pew Internet \& American Life Project. http://www.pewinternet.org/ pdfs/PIP_SNS_Data_Memo_Jan_2007.pdf

Lindley, S. E., Harper, R., \& Sellen, A. (2009). Desiring to be in touch in a changing communications landscape: attitudes of older adults. Proceedings of the 27th international conference on Human factors in computing systems. 1693-1702. ACM. 
McCarthy, H., \& Thomas, G. (2004). Home alone: combating isolation with older housebound people. Demos.London.

Melenhorst, A. S. (2002). Adopting communication technology in later life: The decisive role of benefits. Unpublished doctoral thesis, Technische Universiteit Eindhoven, Eindhoven, the Netherlands.

Nef, T., Ganea, R. L., Müri, R. M., \& Mosimann, U. P. (2013). Social networking sites and older users-a systematic review. International psychogeriatrics/IPA, 1-13.

Nimrod, G. (2010). Seniors' online communities: A quantitative content analysis. The Gerontologist, 50(3), 382-392.

Ofcom (2013). Adults' media use and attitudes report 2013. OFCOM, April 2013.

Office of the Deputy Prime Minister (ODPM) (2005). Excluded older people: social exclusion unit interim report, London: ODPM.

Peace, S., Holland, C. \& Kellaher, L.(2005). Environment and identity in later life. Growing Older. Maidenhead, UK: Open University Press. Cited in Research Findings: 18 From the Growing Older Programme. ESRC. http://www.growingolder.group.shef.ac.uk/ Go_Findings_18.pdf

Pew Research Center (2014). Older Adults and Technology Use. http://www.pewinternet.org/ 2014/04/03/older-adults-and-technology-use

Righi, V., Sayago, S., \& Blat, J. (2012). Older people's use of Social Network Sites while participating in local online communities from an ethnographical perspective. CIRN 2012 Community Informatics Conference:'Ideals meet Reality', 7-9.

Ryu, M., Kim, S. \& Lee, E. (2009). Understanding the Factors Affecting Online Elderly User's Participation in Video UCC Services. Journal of Computers in Human Behavior, 25(3), 619-632.

Sayago, S., \& Blat, J., (2010). Telling the story of older people e-mailing: an ethnographical study. International Journal of Human-Computer Studies, 68, 105-120

Stanley, M., Moyle, W., Ballantyne, A., Jaworski, K., Corlis, M., Oxlade, D.,\& Young, B. (2010). 'Nowadays you don't even see your neighbours': loneliness in the everyday lives of older Australians. Health \& Social Care in the Community, 18(4), 407-414.

Stroebe, M., \& Schut, H. (1999). The dual process model of coping with bereavement: rationale and description. Death studies, 23(3), 197-224.

Suler, J. (2004). The online disinhibition effect. Cyberpsychology \& Behavior,7(3), 321-326.

Tomaka, J., Thompson, S. and Palacios, R. (2006). The relation of social isolation, loneliness, and social support to disease outcomes among the elderly, Journal of Aging and Health, 18, 359-84.

Tornstam, L. (2005). Gerotranscendence. A Developmental Theory of Positive Aging. New York: Springer Publishing.

United Nations (2007). World Economic and Social Survey 2007:Development in an Ageing World. New York. http://www.un.org/esa/policy/wess/wess2007files/wess2007.pdf 
World Health Organisation (2002). Active Ageing: A Policy Framework. http:// whqlibdoc.who.int/hq/2002/WHO_NMH_NPH_02.8.pdf

Wright K. (2000a). Computer-mediated social support, older adults, and coping. Journal of Communication 50 (3), 100-18.

Wright, K. (2000b). The Communication of Social Support Within an On-Line Community for Older Adults: A Qualitative Analysis of the SeniorNet Community. Qualitative Research Reports in Communication, 1 (2), 33-43

Xie, B. (2008). Multimodal Computer-Mediated Communication and Social Support among Older Chinese Internet Users. Journal of Computer Mediated Communication, 13(3), 728-750. 